\title{
Structural changes of corn starch during fuel ethanol production from corn flour
}

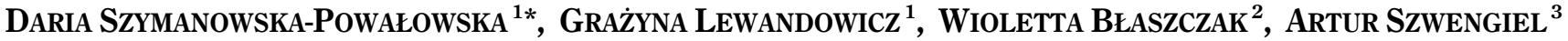 \\ ${ }^{1}$ Department of Biotechnology and Food Microbiology, Poznań University of Life Sciences, Poznań, Poland \\ ${ }^{2}$ Institute of Animal Reproduction and Food Research, Polish Academy of Sciences, Olsztyn, Poland \\ ${ }^{3}$ Department of Fermentation and Biosynthesis, Poznań University of Life Sciences, Poznań, Poland \\ *Corresponding author: darszy@up.poznan.pl
}

\begin{abstract}
The key factor in production of fuel ethanol by simultaneous saccharification and fermentation is the efficient conversion of granular starch into ethanol. Most difficult stage in the process is the enzymatic hydrolysis of starch granules. Their supramolecular structure as well as crystallinity and presence of complexing agents are key factors for the hydrolysis process. The aim of the study was to examine structural changes in starch granules during the simultaneous processes of saccharification and fermentation of corn flour in the long-term repeated Simultaneous Saccharification and Fermentation (SSF) process with complete recycling of the stillage liquid fraction. The SSF experiments were performed using corn flour as a raw material, the STARGEN 001 preparation as a hydrolytic enzyme, and Red Star Ethanol Red (Saccharomyces cerevisiae) fermentation yeasts. Residual starch structure after the $4^{\text {th }}$, and the $7^{\text {th }}$ operation cycle was examined using scanning electron microscopy, X-ray diffractometry, IR spectroscopy as well as gel permeation chromatography. In spite of accumulating glycerol, organic acids and inorganic ions in the fermentation broth, the repeated batch SSF process, with stillage recycling into the fermentation phase conducted on corn flour with the use of the STARGEN 001 enzyme preparation, was found to run efficiently. The amount of unhydrolyzed residual starch was independent of the number of operation cycles. Hydrolysis of starch resulted in the formation of porous granules and a small amount of undigested granules and pyramid-shaped residuals. Crystalline and amorphous regions were evenly digested. The molecular mass distribution of residual starch after the SSF process significantly differed from that of native starch both in the region corresponding to amylopectin and to amylose, while the most distinctive changes with respect to the amylopectin/amylose ratio, i.e. in the 4 th cycle the amylopectin content decreased by up to $19 \%$.
\end{abstract}

Key words: ethanol, simultaneous saccharification and fermentation, native corn starch

\section{Introduction}

Biological technologies of ethanol production have been known for a long time (Lim et al., 2003; Kosaric et al., 1996). They involve process of initial starch processing, i.e. starch gelatinization at high temperature followed by enzymatic hydrolysis. These two processes are characterized by high energy consumption, usually accounting for approx. 30 to $40 \%$ of entire energy required for ethanol production (Lim et al., 2003). There is a constant pursuit for energy-efficient technologies that would ensure high productivity and cost effectiveness. One of the possible ways to achieve this is using a direct one-step method for ethanol production by simultaneous hydrolysis and fermentation in one SSF (Simultaneous Saccharification and Fermentation) reactor and elimina- tion of the gelatinization step using enzymes that can hydrolyze native starch (Kosaric, 1996; Kroumov et al., 2005). As the immediate utilization of hydrolysis products reduces enzyme inhibition, it is possible to obtain ethanol productivity that is $25-40 \%$ higher when compared with the traditional two-step method (Öhgren et al., 2007). Moreover, using native corn starch in the SSF process makes it possible to considerably reduce the costs of starch mash heating. Additionally, SSF decreases the costs and duration of the process, since it is no longer necessary to use two separate fermenters, owing to the elimination of preliminary fermentation stage which takes place already during hydrolysis (Kobayashi et al., 1998). Since hydrolysis usually requires higher temperatures than fermentation, finding optimum 
conditions, i.e. ambient temperature and acidity suitable for both processes, poses a serious problem. For most strains of distiller's yeast, the optimal growth temperature is $30-32^{\circ} \mathrm{C}$, whereas in the SSF process, the temperature of the medium is $35-37^{\circ} \mathrm{C}$, which is higher than the tolerance limit of distiller's yeast (Mensonides et al., 2002; Laluce et al., 2002).

Starch can be hydrolyzed in its native, granular form and this process occurs efficiently in plants. However, commercial enzyme preparations commonly used in the starch-processing industry such as Thermamyl (Novozymes, Denmark), an outstandingly heat-stable $\alpha$-amylase produced by genetically modified Bacillus strains, or BAN 480L (Novozymes, Denmark), a bacterial $\alpha$-amylase produced by selected strains of Bacillius amyloliquefaciens, are effective only towards gelatinized starch (Sarikaya et al. 2000; Uhling, 1998). These enzymes were designed for applications in processes carried out at elevated temperatures in order to improve the reaction kinetics. It is known that gelatinization considerably enhances the reactivity of starch towards amylolytic enzymes. Hydrolysis of granular starch is significantly slower than that of dissolved starch, as the former process requires the step of unwinding of double helix in starch macromolecules. Thus, chains with restricted mobility, i.e. complexed or crystallized, are hydrolyzed with difficulty (Oates, 1997). The efficiency of enzymatic hydrolysis of granular starch depends on its origin, because different starches vary considerably in terms of their supramolecular structure (Oates, 1997; Dona et al., 2010). A comparison of the four cheapest commercial native starches in terms of their susceptibility to amylolysis allows us to set them in the following diminishing order: corn $\geq$ wheat > cassava > potato (Sarikaya et al., 2000; Piyachomkwan et al., 2007).

The susceptibility to enzymatic hydrolysis also largely depends on the enzymes used (Sarikaya et al., 2000), which suggests a potential to genetically engineer better and more efficient enzyme(s) isoforms. A commercial enzymatic preparation exhibiting amylolytic activity to native starch, STARGEN 001, has been recently introduced to the market. STARGEN 001 preparation was developed by Genencor International (Palo Alto, CA) and it is recommended for simultaneous hydrolysis of native starch and ethanol fermentation. This enzyme preparation makes it possible to eliminate double $\mathrm{pH}$ regulation of the medium (liquefaction step - optimal pH 5.0-6.0, the sac- charification step - optimal $\mathrm{pH}$ 4.8-5.0). Furthermore, when using STARGEN 001, there are no limitations related to mash viscosity, so mediums of high density can be used in the process. Employing STARGEN 001 ensures energy and water conservation and results in higher ethanol productivity by avoiding the loss of fermenting sugars, which may occur during heating (the Maillard reaction). Additionally, it does not require the use of an activator, such as calcium ions for most amylases.

There are also two important factors related to water management that determine economic effectiveness of bioethanol production. Firstly, the increasing global water shortage results in an elevation of its costs. Secondly, distillery stillage is ranked among especially burdensome industrial effluents, particularly in large biorefineries. One of the methods to reduce water costs incurred by distilleries is to reutilize stillage in the production process, which not only facilitates reasonable utilization of the by-product, but also significantly reduces the demand for industrial water (Larsson et al., 1997; Montesinos and Navarro, 2000). In order to improve the economical effectiveness of the SSF process, the zero-discharge fermentation system is applied. This means that the solid-containing whole stillage is separated using a decanter centrifuge. Thereafter, the solid phase is dried in a rotary dryer to produce DDGS (Dried Distillers Grain with Solubles), a valuable co-product used for livestock feed, whereas the liquid phase is evaporated in a double-effect evaporator (Białas et al., 2010). Another way of improving this zero-discharge fermentation system is applying the repeated SSF process with complete recycling of the stillage liquid fraction. In such a system, the liquid phase is recirculated into the SSF process (Białas et al., 2010). This methodology meets the requirement of lowering the cost of process water. Scientific literature provides a range of suggestions for the reutilization of distillery stillage for technological purposes (Kim et al., 1997; Lu et al., 2003; Navarro et al., 2000). However, there are few described processes, where the whole stillage or its liquid fraction is repeatedly turned back and reutilized to prepare a new batch of medium. So far the possibility of returning stillage to the SSF process with native starch hydrolysis has not been investigated, therefore a research project on the subject has been designed.

The key factor in the above-described process is connected with efficient conversion of granular starch into 
ethanol. Most difficult stage is the enzymatic hydrolysis of starch granules, in which the key role is played by their supramolecular structure, crystallinity and presence of complexing agents. Aim of the present study was to examine structural changes in starch granules during the simultaneous processes of saccharification and fermentation with full stillage recycling.

\section{Materials and methods}

\section{Microorganism}

Freeze-dried distiller's yeast, Red Star Ethanol Red (Saccharomyces cerevisiae), obtained from Lesaffre Company (Marcq en Baroeul, France) was used in this study for the production of ethanol from corn mashes. The number of the living cells for packing was $>2.0 \times 10^{10} / \mathrm{g}$, as specified by the manufacturer.

\section{Starch material}

Commercially available corn flour (BIO CORN, Ziebice, Poland) was used as a raw material for fermentation. It had a median diameter of $250 \mu \mathrm{m}$ and contained $84 \%$ starch and $0.1 \%$ ash.

\section{Enzymes}

A mixture of granular starch hydrolyzing enzymes, containing Aspergillus kawachi $\alpha$-amylase expressed in Trichoderma reesei, and glucoamylase from Aspergillus niger, was used in this study (STARGEN $001^{\mathrm{TM}}$, Genecor International, Palo Alto, CA). The enzymatic activity of this set of enzymes was $\geq 456$ GSHU/g (Granular Starch Hydrolyzing Units), as specified by Genencore International. In addition, fungal acid protease GC 106 ( $A s$ pergillus niger), also obtained from Genencore International, was added to mashes. The enzymatic activity of GC 106 was $\geq 1000$ SAPU/g (Spectrophotometric Acid Protease Units), as specified by the manufacturer.

\section{Simultaneous saccharification and fermentation}

The SSF experiments were performed in a 51 batch bioreactor (BIOFLO III, New Brunswick Scientific, New Brunswick, NJ) with a 4.01 working volume under nonaerated conditions, at $35^{\circ} \mathrm{C}, 200 \mathrm{rpm}$. A slurry of raw corn flour in water $(25 \% \mathrm{w} / \mathrm{v})$ was prepared and saccharification was carried out by adding $2.05 \mathrm{ml}$ (per kg corn flour dry matter) of Granular Starch Hydrolyzing (GSH) enzyme preparation (STARGEN 001). $\mathrm{pH}$ of the fermentation broth was measured at each sampling and adjusted to 5.0 by an addition of either $10 \% \mathrm{H}_{2} \mathrm{SO}_{4}$ or $20 \%$
$\mathrm{NaOH}$. In all cases, the medium was supplemented with acid protease GC 106 (40 $\mu \mathrm{l} / \mathrm{kg}$ corn flour dry matter) and chloramphenicol $(50 \mathrm{mg} / \mathrm{l}$ of the fermentation medium). Fermentation was started by the addition of freeze-dried distiller's yeast Red Star Ethanol Red $(0.5 \mathrm{~g} / \mathrm{l}$ of fermentation medium). The conditions of SSF process were optimized using the multifactorial experimental approach (Bialas et al., 2009). Samples were obtained and analyzed for starch, glucose and ethanol concentrations after fermentation.

\section{Recycling of stillage}

After the fermentation period was completed, mash containing ethanol was pumped to a continuous distillation column (UOP3CC, Armfield, UK). At the top of this column, operating at $78.5^{\circ} \mathrm{C}$ and reflux ratio of $4: 1$, carbon dioxide was stripped from the ethanol solution which led to (an) ethanol concentration of 93-95\% (volume based) in the side stream. The liquid fraction collected at the bottom of the distillation column was first cooled down to $30^{\circ} \mathrm{C}$ and then centrifuged at $4000 \times g$ for $20 \mathrm{~min}$. The supernatant was used instead of water to dilute native corn starch for the next SSF run. The recirculation of stillage was performed at a constant recirculation degree, with $75 \%$ of fresh water being replaced.

\section{Analysis of starch structure}

Samples from the $4^{\text {th }}$ and $7^{\text {th }}$ fermentation cycles were taken for analyses. The structure of the starch fraction in corn flour was also examined.

The morphology of starch granules was examined by scanning electron microscopy (SEM). Starch samples for analyses were isolated and prepared as follows: corn flour or the sediments after the $4^{\text {th }}$ and the $7^{\text {th }}$ fermentation cycles were suspended in a $20 \% \mathrm{NaOH}$ solution and shaken for 10 minutes at room temperature. Then, the samples were centrifuged at $4000 \times g$ for 15 minutes. Starch fractions were collected and purified by repeatedly suspending in water, shaking and centrifugation. Finally, the purified granules were dried and then deposited on a copper disc, coated with gold using a Jeol JEE 400 vacuum evaporator and analyzed under an SEM (Jeol JSM 5200) at $10 \mathrm{kV}$ accelerating voltage.

Gel permeation chromatography (GPC) was carried out using a Waters Company apparatus (Alliance HPLC System 2695) equipped with a refractometric detector (RI) Waters 2414. Three UltrahydrogelTM columns arranged in a series were used. The obtained data were 


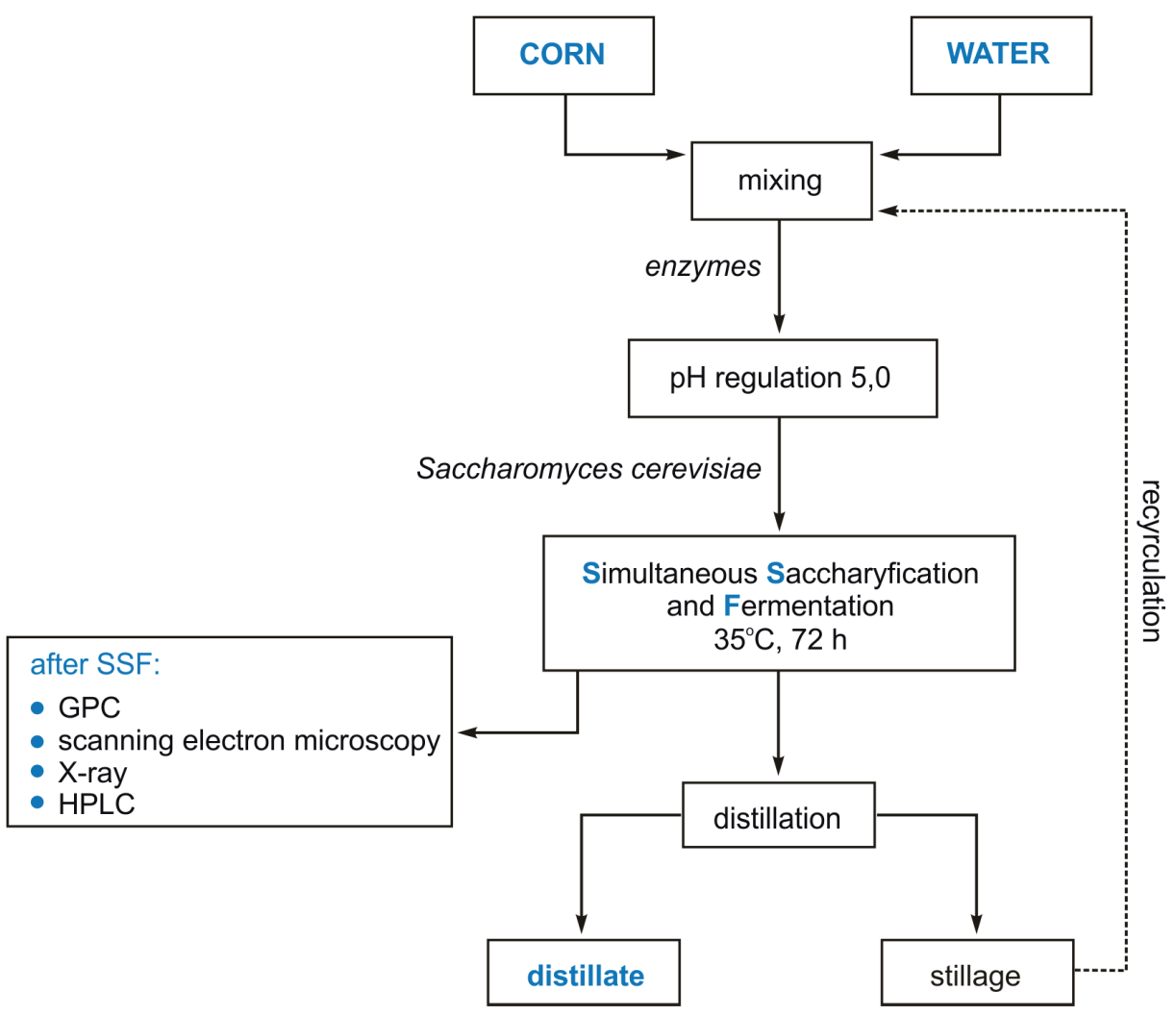

Fig. 1. Flow sheet of the experiment

Table 1. Time course of SSF processes with stillage recycling after hydrolysis in the $4^{\text {th }}$ and the $7^{\text {th }}$ cycle of the SSF process

\begin{tabular}{c|c|c|c|c|c}
\hline $\begin{array}{c}\text { Fermentation } \\
\text { time } \\
{[\mathrm{h}]}\end{array}$ & $\begin{array}{c}\text { Operational } \\
\text { cycle }\end{array}$ & $\begin{array}{c}\text { Ethanol } \\
\text { content } \\
{[\mathrm{g} / \mathrm{l}]}\end{array}$ & $\begin{array}{c}\text { Starch } \\
\text { content } \\
{[\mathrm{g} / \mathrm{l}]}\end{array}$ & $\begin{array}{c}\text { Disaccharides } \\
\text { content } \\
{[\mathrm{g} / \mathrm{l}]}\end{array}$ & $\begin{array}{c}\text { Glucose } \\
\text { content } \\
{[\mathrm{g} / \mathrm{l}]}\end{array}$ \\
\hline 0 & $4^{\text {th }}$ & $0 \pm 0.00^{*}$ & $210 \pm 0.12$ & $0.2 \pm 0.03$ & $15.1 \pm 0.55$ \\
\hline 0 & $7^{\text {th }}$ & $0 \pm 0.00$ & $210 \pm 0.17$ & $0.5 \pm 0.05$ & $12.9 \pm 0.22$ \\
\hline 72 & $4^{\text {th }}$ & $87 \pm 0.54$ & $43 \pm 0.61$ & $0.4 \pm 0.03$ & $2.1 \pm 0.09$ \\
\hline 72 & $7^{\text {th }}$ & $91 \pm 0.32$ & $40 \pm 0.52$ & $0.1 \pm 0.01$ & $9.2 \pm 0.08$ \\
\hline
\end{tabular}

* Three repetitions of measurement were conducted for each sample, the given standard deviation concerns measurement variability

processed using Empower Pro software (Waters) in the GPC option. The following parameters were applied during the chromatographic analysis: injector temperature $\left(25^{\circ} \mathrm{C}\right)$, column temperature $\left(40^{\circ} \mathrm{C}\right)$, measuring cell temperature $\left(35^{\circ} \mathrm{C}\right)$; and the flow rate of the solvent (deionised water, $0.700 \mathrm{ml} / \mathrm{min})$. Starch samples $(4 \mathrm{mg} / \mathrm{ml}$ ) were dissolved in distilled water during the autoclaving process $\left(121^{\circ} \mathrm{C}, 15 \mathrm{~min}\right)$. GPC molecular weight distribution calculations were performed using the calibration curve that was based on dextran standards at the $\mathrm{M}_{\mathrm{w}}$ range of $11 \times 10^{4}$ to $1 \times 10^{6}$ (Polymer Standards Service Gmbh, Mainz Germany) and Blue Dextran standards (Sigma, St. Louis, MO, USA).

The X-ray diffractometry was performed with a TUR 62 Carl Zeiss X-ray diffractometer under the following conditions: X-ray tube CuKa (Ni filter), voltage $30 \mathrm{kV}$, current $15 \mathrm{~mA}$, scanning from $\mathrm{Q}=2^{\circ}$ to $18^{\circ}$. To avoid the influence of relative humidity on relative crystal- 


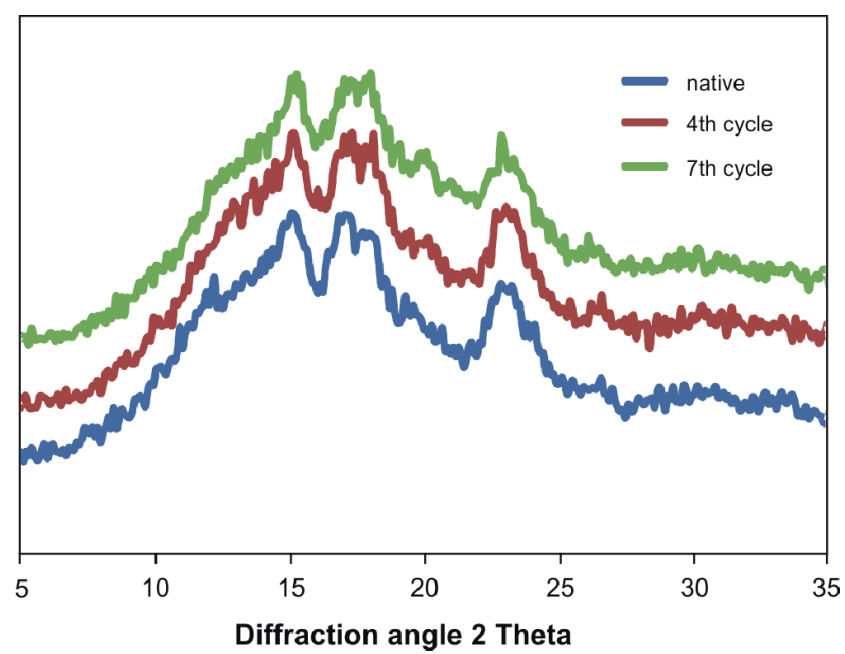

Fig. 2. X-ray diffraction patterns of corn starch: native, hydrolyzed in the $4^{\text {th }}$ and the $7^{\text {th }}$ cycle of the SSF process

linity, starch samples were placed in a desiccator and conditioned for $48 \mathrm{~h}$ in the atmosphere of $92 \%$ relative humidity.

The Fourier Transform Infrared Spectroscopy (FTIR) measurements were performed in the solid state with a FTIR Bruker IFS 113v spectrometer under the following conditions: $\mathrm{KBr} /$ pellet $(200 \mathrm{mg} / 1.5 \mathrm{mg})$, resolution at $2 \mathrm{~cm}^{-1}$.

\section{Analytical methods}

Samples for chemical analyses were first centrifuged at $4000 \times g$ for $10 \mathrm{~min}$. at $4{ }^{\circ} \mathrm{C}$ (Multifuge 3SR, Germany), filtered through a $0.22 \mu \mathrm{m}$ membrane filter (MillexGS, Millipore, USA) and then analyzed on an HPLC system (Merck Hitachi, Germany). Glucose, disaccharides and ethanol were separated on an Aminex HPX-87P apparatus (Bio-Rad, USA) at $30^{\circ} \mathrm{C}$ using $5 \mathrm{mM} \mathrm{H}_{2} \mathrm{SO}_{4}$ solution as the mobile phase at a flow rate of $0.6 \mathrm{ml} / \mathrm{min}$, and then detected with a refractive index detector (Model L-7490, Merck Hitachi, Germany). The starch content was analyzed according to the enzymatic method developed by Holm et al. (1986). Block diagram of the experiment is demonstrated in Fig. 1.

\section{Results and discussion}

The repeated batch SSF process with stillage recycling was conducted on native starch, with the use of novel GSH enzymes, potentially being an alternative for the traditional technology of fuel ethanol production. Detailed results of the analysis of combined hydrolysis and

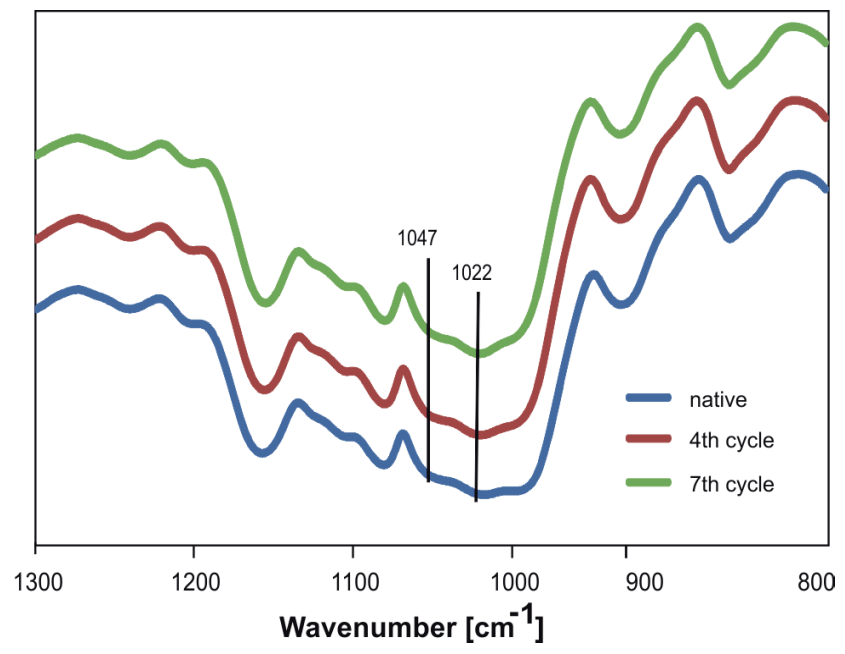

Fig. 3. IR spectra of corn starch: native, hydrolyzed in the $4^{\text {th }}$ and the $7^{\text {th }}$ cycle of the SSF process

fermentation process were presented by Białas et al. $(2009,2010)$. Within this study, only $4^{\text {th }}$ and $9^{\text {th }}$ fermentation cycles were investigated (Table 1).

As a result of fermentation of native corn starch after 72-h fermentation, the concentration of ethanol was $87 \mathrm{~g} / \mathrm{l}$ for the $4^{\text {th }}$ and $91 \mathrm{~g} / 1$ for the $7^{\text {th }}$ cycle. Starch utilization rate in both cases was approximately $80 \%$, while process efficiency accounted for $78 \%\left(4^{\text {th }}\right)$ and $84 \%\left(9^{\text {th }}\right)$ theoretical yield. The probable cause of incomplete substrate utilization in SSF process was decrease in the activity of amylolytic enzymes contained in STARGEN. It could have also been caused by mash acidification below optimal $\mathrm{pH}$. Actions aimed at intensifying starch hydrolysis (like increasing enzyme addition, $\mathrm{pH}$ regulation, increasing stirring rate) would not be economically justified taking into account the high yield of fermentation process.

According to the data supplied by Genecor International Inc., theoretically, when using STARGEN 001 and corn mash of $33 \%$ s.s. density, final ethanol concentration of $16-18 \%$ may be obtained. However, these values have not been confirmed by any publications or descriptions of currently run production processes. Deviations of results recorded in this study from the values reported by the enzyme manufacturer may be caused by several reasons. A considerable role is played by the raw material - its origin, species and strain, which influences the proportions of individual starch fractions, and also by the milling rate of flour itself, which determines starch availability for enzymes. The SSF process using STAR- 

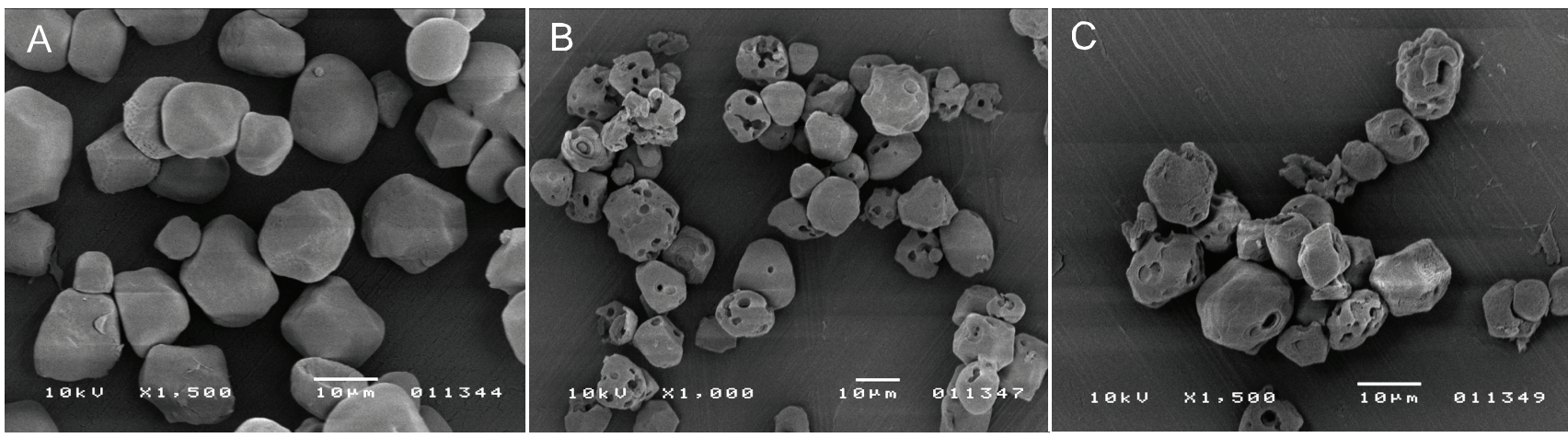

Fig. 4. Scanning electron micrographs (SEM) of corn starch: native (A), hydrolyzed in the $4^{\text {th }}(\mathrm{B})$ and the $7^{\text {th }}$

(C) cycle of the SSF process

Table 2. Molecular weight distribution of native corn starch and corn starch hydrolyzed in the $4^{\text {th }}$ and the $7^{\text {th }}$ cycle of the SSF process ${ }^{\text {a, b }}$

\begin{tabular}{l|c|c|c|c|c|c}
\hline \multirow{2}{*}{\multicolumn{1}{c}{ Fraction }} & \multicolumn{2}{c|}{ Native starch } & \multicolumn{2}{c|}{$4^{\text {th }}$ cycle } & \multicolumn{2}{c}{$7^{\text {th }}$ cycle } \\
\cline { 2 - 7 } & $\mathrm{M}_{\mathrm{w}}(\mathrm{g} / \mathrm{mol})$ & area $(\%)$ & $\mathrm{M}_{\mathrm{w}}(\mathrm{g} / \mathrm{mol})$ & area $(\%)$ & $\mathrm{M}_{\mathrm{w}}(\mathrm{g} / \mathrm{mol})$ & area $(\%)$ \\
\hline Amylopectin & $1.53 \times 10^{6}$ & 64.2 & $1.49 \times 10^{6}$ & 45.1 & $1.54 \times 10^{6}$ & 58.7 \\
\hline Amylose & $1.07 \times 10^{6}$ & 35.8 & $1.01 \times 10^{6}$ & 54.9 & $1.06 \times 10^{6}$ & 41.3 \\
\hline
\end{tabular}

${ }^{a}$ molecular weights $(\mathrm{g} / \mathrm{mol})$ were calculated on the basis of GPC profiles presented in Fig. 4

${ }^{b}$ coefficient of variation did not exceed $0.3 \%$ for any calculated molecular weight

GEN 001 has also been described previously (Wang et al., 2005 and 2006; Sharma et al., 2007).

There are a number of structural factors that determine starch resistance to enzymatic attack. Its crystal structure is considered to be one of the most important factors in this regard (Planchot et al., 1997). A-type starches, such as those from normal-genotype cereals, are much more susceptible to hydrolysis by $\alpha$-amylase than B-type starches, such as high-amylase cereals or potato starches. Moreover, it was postulated that the hydrolysis rate of starch granules largely depends on the distribution of semi-crystalline and crystalline layers (Gallant et al., 1997). This hypothesis was confirmed by SEM analysis of residual starch granules after partial $\alpha$-amylase hydrolysis and was the basis of "blocklet" concept of the supramolecular organization of starch (Gallant et al., 1997). Following this hypothesis one could expect that residual starch would exhibit a higher degree of crystallinity than native starch. As it is shown in Fig. 2, residual starch after the SSF process showed no changes in crystallinity in comparison with native starch both in terms of the type of X-ray diffraction pattern and relative crystallinity.
This observation was similar to that made by Zhang et al. (2006) that both crystalline and amorphous regions in native cereal starches are evenly digested by the mixture of $\alpha$-amylase and amyloglucosidase. The above-mentioned discrepancies can be related to different mechanisms of enzymatic hydrolysis catalyzed by enzymes of different biological origin (Robertson et al., 2006). The supramolecular organization of starch may also be examined using IR spectroscopy. According to the data reported by van Soest et al. (1995), the IR spectrum is sensitive to changes in the short-range structure in the $\mathrm{C}-\mathrm{C}$ and $\mathrm{C}-\mathrm{O}$ stretching regions at $1300-800 \mathrm{~cm}^{-1}$. The absorbance band at $1047 \mathrm{~cm}^{-1}$ is sensitive to the amount of ordered or crystalline starch, while the band at $1022 \mathrm{~cm}^{-1}$ is characteristic of amorphous starch (van Soest et al., 1995). However, the FTIR technique does not differ between the A- and B-type of crystallinity, and the differences observed between different starches are not related to this factor (Sevenou et al., 2002; Lewandowicz and Soral-Śmietana, 2004). The IR examination demonstrated no changes caused by the SSF process either in the functional groups or in the finger-print range (Fig. 3), and even the $1047 \mathrm{~cm}^{-1}$ 


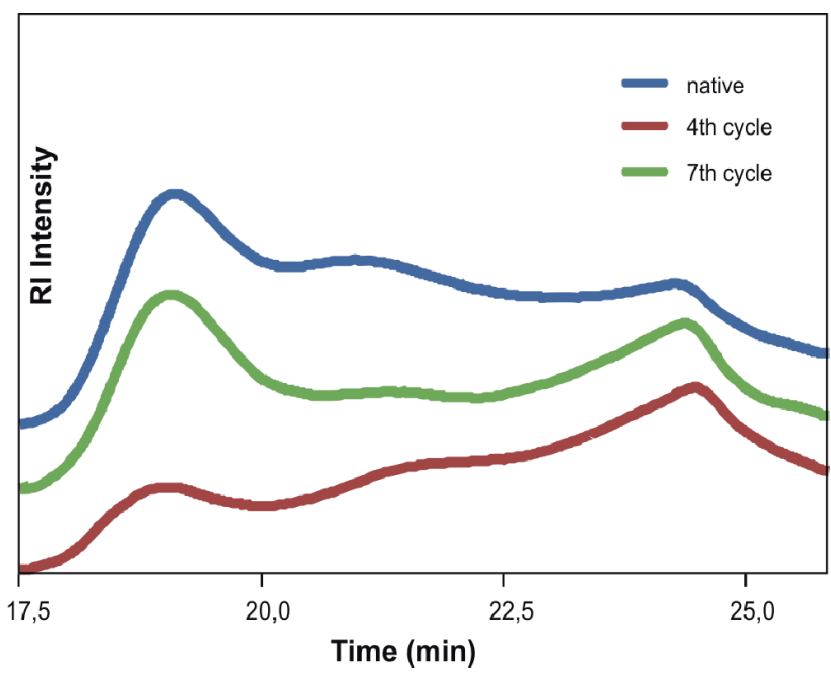

Fig. 5. GPC profiles of corn starch: native, hydrolyzed in the $4^{\text {th }}$ and the $7^{\text {th }}$ cycle of the SSF process

and $1022 \mathrm{~cm}^{-1}$ bands did not change as a result of the hydrolysis process.

According to Planchot et al. (1995), in the first stage of hydrolysis by $\alpha$-amylases normal corn starch granules are randomly furrowed, then the pores are penetrated through the outer shells of granules, and finally the enlarged, individual pores form external grooves and internal corrosion channels. However, it was also reported that native corn starch granules have small pores (more precisely - radial, tube-like channels that connect the central cavity to the external environment) (Sarikaya et al., 2010; Huber and Miller, 1997; Huber and Miller, 2000). Zhang et al. (2006) demonstrated that hydrolysis of native corn starch starts with an increase in pore size until an almost complete fragmentation of the granules. However, in the last stage of hydrolysis, a few undigested small granules exist alongside pyramid-shaped residuals (Gallant et al., 1997). In the SEM images of starch remaining after individual cycles of the SSF process (Fig. 4), starch granules with pores were predominant. Undigested starch granules and pyramid-shaped residuals were less prevalent. The above observation suggests that there is a margin in the SSF process, and the degree of hydrolysis can be enhanced.

The experimental data presented above showed that both amorphous and crystalline fractions were uniformly digested by the STARGEN 001 amylolytic enzyme preparation. Since crystalline regions are formed only by amylopectin (Robertson et al., 2006), both the amylose and the amylopectin fractions should be simultaneously hydrolyzed. This hypothesis was, to some extent, confirmed by the GPC analysis (Fig. 5).

This method is conventionally applied for the determination of molecular weight distribution in polymers. However, in the case of starch, the determination of the actual values of number $\left(M_{n}\right)$ or weight $\left(M_{w}\right)$ average molar masses is especially difficult due to the extremely high molecular mass of amylopectin as well as problems with dissolving starch. As a consequence, the data regarding molecular mass of different native starches reported by different researches vary considerably (Swinkles, 1985; Aberle et al., 1994; Han and Lim, 2004). The main problem in the determination of the molecular weight distribution in starches is associated with dissolving the entire starch sample without cleaving any of the macromolecules. The most frequently recommended starch solvents are aqueous solutions of sodium hydroxide or aqueous di-methyl sulfoxide. However, both the solvent and the solubilization method strongly affect the occurrence of a polysaccharide breakdown. Moreover, the most popular pullulan and dextran molecular weight standards are characterized by slightly different molecular structures and far lower molecular weights when compared to starch, so they can be recommended only for the assessment of the molecular weight of amylose (Lin et al., 2003; Chen et al., 2010; Braun 1993; Jackson, 1991). However, to answer the question regarding the susceptibility of the amylose and amylopectin fractions to amylolysis, knowledge of the absolute values of molecular weight is not essential, in contrast with information on the changes in both molecular weight and percentage of individual fractions. As it is shown in Figure 5 and Table 2, the molecular mass distribution of residual starch after the SSF process actually differed from that of native starch both in the region corresponding to amylopectin and amylose. These changes were mainly in regard to the amylopectin/amylose ratio. As a result of the SSF process, proportion of the lowmolecular fraction (amylose) increased. This phenomenon strongly confirmed the statement of the Zhang group on an even digestion of the amylose and amylopectin fractions during amylolysis of starch granules (Zhang, 2006).

\section{Conclusions}

In conclusion, it needs to be stated that the enzymatic preparation produced by Genencor International 
using genetically modified microorganisms provides effective hydrolysis of native corn starch, owing to which efficiency of ethanol production may be increased with a simultaneous cost reduction as a result of the elimination of the energy-intensive starch liquefaction process run at high temperatures. The amount of unhydrolyzed residual starch is independent of the number of operation cycles. Hydrolysis of starch occurs with the predominant formation of granules with pores as well as an additional small amount of undigested granules and pyramid-shaped residuals. Crystalline and amorphous regions are evenly digested. This observation is also confirmed by the determination of changes in molecular mass distribution caused by the SSF process.

\section{Acknowledgements}

This work was supported by the Polish Ministry of Science and Higher Education under R\&D Grant No. 0619/P01/2007/02.

\section{References}

Aberle T.H., Burchards W., Vorweg W., Radosta S. (1994) Conformational contributions of amylose and amylopectin to the structural properties of starch from various sources. Starch/Stärke 46(9): 329-225.

Białas W., Szymanowska D., Grajek W. (2010) Fuel ethanol production from granular corn starch using Saccharomyces cerevisiae in a long term repeated SSF process with full stillage recycling. Biores. Technol. 101: 3126-3131.

Białas W., Wojciechowska D., Szymanowska D., Grajek W. (2009) Optimization of simultaneous saccharification and fermentation of native starch using response surface method. Biotechnologia 4(87): 183-199 (in Polish).

Braun K. (1993) Determination of the molecular weight distribution of starch. Carbohydr. Netherl. 9: 35-37.

Chen C.J., Shen Y.C., Yeh A.I. (2010) Physico-chemical characteristics of media-milled corn starch. J. Agr. Food Chem. 58: 9083-9091.

Dona A.C., Pages G., Gilbert R.G., Kuchel P.W. (2010) Digestion of starch: In vivo and in vitro kinetic models used to characterize oligosaccharides or glucose release. Carbohydr. Polymer. 80: 599-617.

Gallant D.J., Bouchet B., Baldwin P.M. (1997) Microscopy of starch: evidence of a new level of granule organization. Carbohydr. Polymer. 32: 177-191.

Han J.A., Lim S.T. (2004) Structural changes of corn starches by heating and stirring in DMSO measured by SECMALLS-RI system. Carbohydr. Polymer. 55: 265-272.

Holm J., Björck I., Drews A., Asp N.G. (1986) A rapid method for the analysis of starch. Starch/Stärke. 38: 224-226.

Huber K.C., Miller J.N. (1997) Visualisation of channels and cavities of corn and sorghum starch granules. Cereal Chem. 74(5): 537-541.
Huber K.C., Miller J.N. (2000) Channels of maize and sorghum starch granules. Carbohydr. Polymer. 41: 269-276.

Jackson D.S. (1991) Solubility behaviour of granular corns starches in methyl sulfoxide (DMSO) and measured by high performance size exclusion chromatography. Starch/Stärke. 43: 422-427.

Kim J.S., Kim B.G., Lee Ch.H., Kim S.W., Jee H.S., Koh J.H., Fane A.G. (1997) Development of clean technology in alcohol fermentation industry. J. Clean. Prod. 5: 263-267.

Kobayashi F., Sawada T., Nakamura Y., Ohnaga M., Godliving M., Ushiyama T. (1998) Saccharification and alcohol fermentation in starch solution of steam-exploded potato. Biotechnol. Appl. Biochem. 69: 177-189.

Kosaric N. (1996) Ethanol - potential source of energy and chemical product. In: Biotechnology. Products of Primary Metabolism 6, ed. Rehm H.J., Reed G., Puhler A., Stadler P., VCH, Germany: 121-198.

Kroumov A.D., M'Odenes A.N., De Araujo Tait M.C. (2005) Development of new unstructured model for simultaneous saccharification and fermentation of starch to ethanol by recombinant strain. Biochem. Eng. J. 28: 243-255.

Laluce C., Souza C.S., Abud C.L., Gattas E.A.L., Walker G.M. (2002) Continuous ethanol production in a nonconventional five-stage system operating with yeast cell recycling at elevated temperatures. J. Ind. Microb. Biotech. 29(3): 140-144.

Larsson M., Galbe M., Zacchi G. (1997) Recirculation of process water in the production of ethanol from softwood. Bioresour. Technol. 60(2): 143-151.

Lewandowicz G., Soral-Śmietana M. (2004) Starch modification by iterated syneresis. Carbohydr. Polymer. 56: 403-413.

Lim L.H., Macdonald D.G., Hill G.A. (2003) Hydrolysis of starch particles using immobilized barley [alpha]-amylase. Biochem. Eng. J. 13: 53-62.

Lin J.H., Lee S.Y., Chang Y.H. (2003) Effect of acid-alcohol treatment on the molecular structure and physicochemical properties of maize and potato starch. Carbohydr. Polymer. 53: 475-482.

Lu X., Li Y., Duan Z., Shi Z., Mao Z. (2003) A novel, repeated fed-batch, ethanol production system with extremely long term stability achieved by fully recycling fermented supernatants. Biotechnol. Lett. 25(21): 1819-1826.

Navarro A.R., Sepulveda M., Del C., Rubio M.C. (2000) Bioconcentration of vinasse from the alcoholic fermentation of sugar cane molasses. Waste Managem. 20(7): 581-585.

Mensonides F.I.C., Schuurmans J.M., Teixeria De Mattos M.J., Hellingwerf K.J., Brul S. (2002) The metabolic response of Saccharomyces cerevisiae to continuous heat stress. Mol. Biol. Rep. 29(1-2): 103-106.

Montesinos T., Navarro J.M. (2000) Production of alcohol from raw wheat flour by amyloglucosidase and Saccharomyces cerevisiae. Enzyme Microbial. Technol. 27(6): 362-370.

Oates C.G. (1997) Towards an understanding of starch granule structure and hydrolysis. Trends Food Sci. Tech. 8: 375-382.

Öhgren K., Bura R., Lesnicki G., Saddler J., Zacchi G. (2007) A comparison between simultaneous saccharification and 
fermentation and separate hydrolysis and fermentation using steam-pretreated corn stover. Process Biochem. 42(5): 835-839.

Piyachomkwan K., Wunsuksri R., Wanlapatit S., Chatakanonda P., Sriroth K. (2007) Application of granular starch hydrolyzing enzymes for ethanol production. In: Starch. Progress in Basic and Applied Sciences, ed. Tomasik P., Yuryev V., Bertoft E., Polish Society of Food Technologists, Małopolska Branch, Kraków: 183-190.

Planchot V., Colonna P., Gallant D.J., Bouchet B. (1995) Extensive degradation of native starch granules by alpha-amylase from Aspergillus fumigates. J. Cereal Sci. 21: 163-171.

Planchot V., Colonna P., Buleon (1997) An enzymatic hydrolysis of $\alpha$-glucan crystallites. Carbohydr. Res. 298: 319-326.

Robertson G.H., Wong D.W.S., Lee C.C., Wagschal K., Smith M.R., Orts W.J. (2006) Native or raw starch digestion: A key step in energy efficient biorefining of grain. J. Agr. Food Chem. 54: 353-365.

Sarikaya E., Higasa T., Motoyasu A., Mikami B. (2000) Comparison of degradation abilities of $\alpha$-and $\beta$-amylases on raw starch granules. Process Biochem. 35: 711-715.

Sevenou O., Hill S.E., Farhat J.R., Mitchell J.R. (2002) Organisation of the external region of the starch granule as determined by infrared spectroscopy. Int. J. Biol. Macromol. 31: 79-85.

Sharma V., Singh V., Rausch K.D., Tumbleson M.E. (2007) Comparison between granular starch hydrolyzing enzyme and conventional enzymes for ethanol production from maize starch with different amylose: amylopectin ratios. Starch/Stärke 59(11): 549-556.

Swinkles J.J.M. (1985) Composition and properties of commercial native starches. Starch/Stärke. 37(1): 1-5.

Uhling H. (1998) Industrial Enzymes and Their Applications. Translated and updated by Elfried M. Linsmaier-Bednar, Ph.D. New York.

van Soest J.J.G., Tournois H., de Wit D., Vliegenthart J.F.G. (1995) Short-range structure in (partially) crystalline potato starch determined with attenuated total reflectance Fourier-transform IR spectroscopy. Carbohydr. Res. 279: 201-214.

Wang P., Singh V., Xu L., Rausch K.D., Tumbleson M.E., Johnston D.B. (2005) Comparison of enzymatic (E-Mill) and conventional dry-grind corn processes using a granular starch hydrolyzing enzyme. Cereal Chem. 82: 734-738.

Wang P., Singh V., Xue H., Johnston D.B., Rausch K.D., Tumbleson M.E. (2006) Comparison of raw starch hydrolyzing enzyme with conventional liquefaction and saccharification enzymes in dry-grind corn processing. Cereal Chem. 84: 10-14.

Zhang G., Ao Z., Hamaker B.R. (2006) Slow digestion property of native cereal starches. Biomacromolecules 7: 3252-3258. 